\title{
Marcel Vernooij*
}

\section{TRADE \& ENVIRONMENT - DO NO HARM, DO GOOD, BE GOOD}

Trade is an engine of economic growth, employment and business innovation. It can be a powerful lever to promote sustainable development, for the benefit of both women and men, in harmony with nature and the environment. All actors that are directly or indirectly involved in international trade have the responsibility to guarantee a "good trade". This article clarifies the relationship between trade and the environment along global supply chains as key elements for sustainable development. Drawing on personal experience, we address several global topics and highlight some very promising initiatives coming from the business world.

\section{Comercio y medioambiente: no hacer daño, hacer el bien, ser bueno}

El comercio es un motor de crecimiento económico, de empleo e innovación empresarial. Puede llegar a ser una vigorosa fuerza en favor del desarrollo sostenible, en beneficio de mujeres y hombres, en armonía con la naturaleza y el medioambiente. Todos los actores que de forma directa o indirecta participan en el comercio internacional, tienen la responsabilidad de garantizar un «comercio bueno». Este artículo aclara la interrelación entre el comercio y el medioambiente a lo largo de las cadenas internacionales de valor, como elementos fundamentales del desarrollo sostenible. Basándome en mi experiencia personal, abordaremos diversos temas globales de discusión y destacaremos algunas iniciativas muy prometedoras que proceden del mundo empresarial.

Keywords: trade and environment, sustainable development, WTO.

Palabras clave: comercio y medioambiente, desarrollo sostenible, OMC. JEL: F18.

\footnotetext{
* Marcel Vernooij is heading the economic division of the Permanent Representation of the Kingdom of the Netherlands in Geneva, and is Deputy Permanent Representative to the World Trade Organization (WTO). In his career, he has represented his country in many multilateral organizations, including the Convention on Biological Diversity, the International Union for the Conservation of Nature and the Commission on Sustainable Development, as well as in bilateral dialogues with several partner countries. He is a biologist, with a specialization in environmental sciences. He has written this article in his personal capacity.

Contact: ml.vernooij@hetnet.nl

Final version September 2021.

https://doi.org/10.32796/ice.2021.922.7289
} 


\section{Introduction}

Trade is an engine for economic growth, jobs an innovative entrepreneurship. It can be a major force for sustainable development, for the benefit of women and men alike, while being respectful to nature and the environment. The responsibility to ensure such "trade for good" rests upon all stakeholders directly or indirectly involved in trade.

This article sheds some light on the interface of trade and the environment along international value chains, as integrated components of sustainable development. Given my personal experience, I will focus on global dialogues, and provide illustrations of inspiring results, delivered by and for business.

\section{Mutually supportive}

In essence, trade can be seen as making logistical connections, and transport a good or service from point $A$ to point $B$. Proper communication and reliable transfer of money facilitate it. In economic terms, trade is a mechanism for supply to meet demands. International trade links a producer, with her/his dedication, skills and opportunities in one country, to a consumer with his/her willingness to purchase in another country. It is a link often via long, complex, multidimensional value chains, crossing borders of several countries.

However, trade is much more than that. People directly involved in shaping the trade corridor all have their own values and norms. The global "value" chain can only function in respect of their diversity, while continuously molding a minimal common understanding of principles and rules needed to make trade happen. Since trade has linking pins in both production and consumption, many more people are involved, be it as citizen, consumer, worker, or entrepreneur. They may rightfully expect that traded goods and services are produced in an ecologically and socially responsible manner. Bringing sustainable goods and services to markets is all about adding economic, as well as societal value. In the end there has to be a fair reward for all, if trade is to be a force for good (in essence: Figure 1).

The global, multilateral dialogue on the interrelationship between trade and environment (policies) of today has deep roots. The dialogue has been part of structured multilateral cooperation on environmental matters, which was brought to a higher plan in 1972 with the foundation of the United Nations Environment Programme (UNEP). ${ }^{1}$ In the same period, countries took it on board in their multilateral cooperation on trade, including in a Working Group on Environmental Measures and International Trade established under the General Agreement on Tariffs and Trade (GATT). It was however not until 1995 before they placed environmental issues structurally on the agenda of global trade deliberations, with the establishment of the Committee on Trade and Environment (CTE), immediately after the World Trade Organization (WTO) started operating (Teehankee, 2020).

In their decision establishing the CTE, ministers underlined that:

"There should not be, nor need be, any policy contradiction between upholding and safeguarding an open, non-discriminatory and equitable multilateral trading system on the one hand, and acting for the protection of the environment, and the promotion of sustainable development on the other."

At the CTE WTO-members comprehensively exchange views on the coherence of international agreements for trade and for the environment. Standing agenda items furthermore include: trade-related national environmental measures, eco-labelling and

\footnotetext{
At the United Nations Environment Programme (UNEP), work on trade is channeled via the Environment and Trade Hub. Countries are supported with research, capacity building and policy advisory services, in seeking to leverage trade and investment for achieving the Sustainable Development Goals and climate commitments. WTO and UNEP cooperate in providing services to countries.
} 


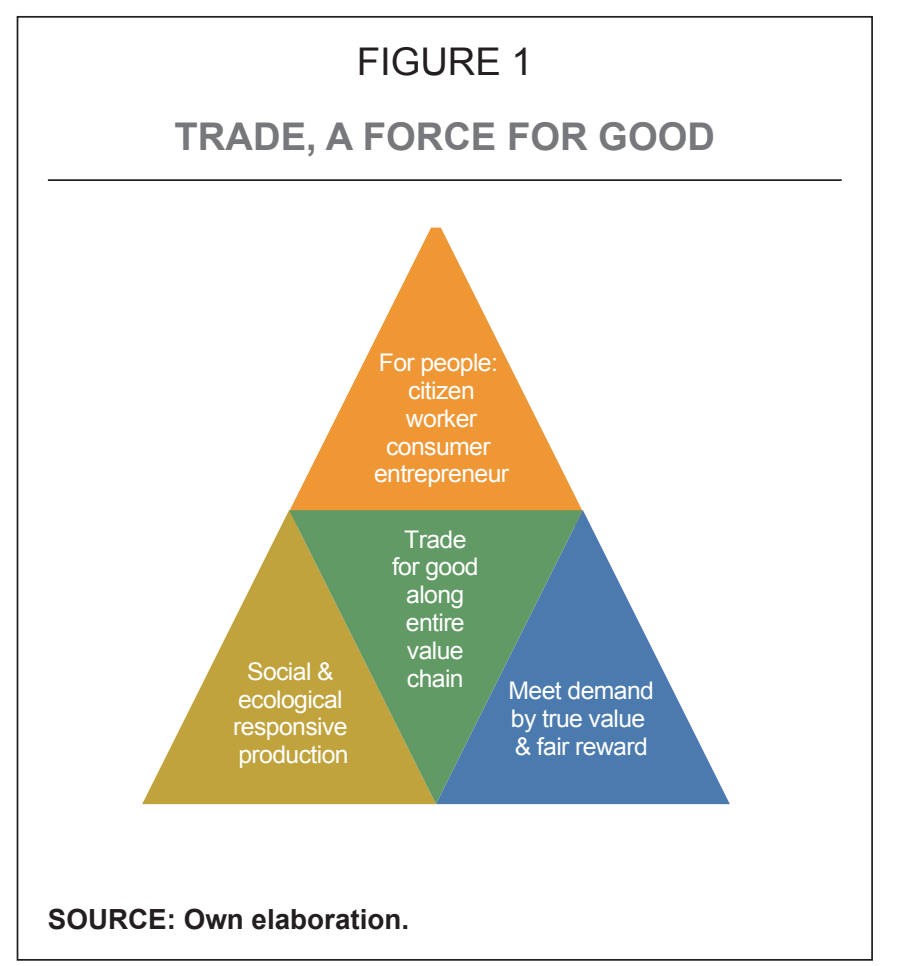

market access. The CTE also has been the forum for negotiations to liberalize trade in environmental goods and services.

Today's global trade rules offer opportunities for countries to adopt a wide range of environmental measures. A basic condition is that such measures comply with WTO rules: they cannot be applied arbitrarily between domestic and foreign producers and cannot be used openly or disguised as (green) protectionism. The Marrakesh Agreement Establishing the WTO enables members to develop environmental measures in harmony with trade policy, and it recognizes that Parties do so actively:

"Their relations in the field of trade and economic endeavor should be conducted [...] while allowing for the optimal use of the world's resources in accordance with the objective of sustainable development, seeking both to protect and preserve the environment and to enhance the means for doing so in a manner consistent with their respective needs and concerns at different levels of economic development."
In other words: trade policy should not work against, and whenever possible work for the environment. Environment measures should not arbitrarily block trade, nor discriminate against foreign companies.

The legal coherence of WTO Agreements and Multilateral Environmental Agreements (MEAs) has been a matter of fierce debate in the governing bodies of the international organizations established under these agreements. It is also subject of scientific studies and deliberations. Should there be any hierarchical relationship among those agreements? Should certain obligations of one prevail over those of the other? What to do in situations where trade is relevant for countries, when they have ratified a different set of agreements? Most pertinent for the global challenges we face today, climate change and the loss of biological diversity, is that it continues to be legally disputed, whether and how one or more countries can unilaterally apply trade measures to protect nature and the environment beyond their national jurisdiction. This is one of the major issues for designing, for example, carbon border adjustment mechanisms, that are the least trade distorting and non-discriminatory measure, of which more will be discussed at the end of this article.

Nevertheless, the overall perception today is that trade and environmental rules are mutually supportive. A clear example is one of the more recent instruments of international environmental law, the Cartagena Biosafety Protocol under the UNCBD, United Nations Convention on Biological Diversity (2000). In accordance with the precautionary approach, the objective of this Protocol is to contribute to ensuring adequate protection in the field of the safe transfer, handling and use of living modified organisms resulting from modern biotechnology. The Protocol applies to the transboundary movement, transit, handling and use of all living modified organisms that may have adverse effects on the conservation and sustainable use of biological diversity, taking also into account risks to human health. After intensive negotiations, countries 


\section{TABLE 1}

\section{PROMOTING TRADE IN TROPICAL TIMBER FROM SUSTAINABLY MANAGED FORESTS}

The objectives of the International Tropical Timber Agreement 2006 (ITTA) are "to promote the sustainable management and conservation of tropical forests, and to promote the expansion and diversification of international trade in tropical timber from sustainably managed and legally harvested forests". The present agreement succeeds versions adopted in 1983 and in 1994. The International Tropical Timber Organization (ITTO) is the intergovernmental organization supporting its 74 members in the implementation of their commitments, all of which are also members of the WTO. It has developed policy guidelines and norms to encourage sustainable forest management and sustainable tropical timber industries and trade. Tropical member countries can get assistance to adapt such guidelines and norms to local circumstances and implement them in the field. Producer and consumer members jointly promote sustainable tropical timber supply chains. ITTO works together with CITES and the Convention on Biological Diversity. This global cooperation is complimented by regional and bilateral trade agreements. The European Union for example has entered into complimentary agreements with its trading partners, including on Forest Law Enforcement, Governance and Trade (FLEGT).

SOURCE: International Tropical Timber Organization. https://www.itto.int/

reached a conclusion on the interrelationship of trade and environment, as reflected in the preamble:

\section{Recognizing that}

trade and environment agreements should be mutually supportive with a view to achieving sustainable development,

\section{Emphasizing that}

this Protocol shall not be interpreted as implying a change in the rights and obligations of a Party under any existing international agreements,

Understanding that
the above recital is not intended to
subordinate this Protocol to other
international agreements.

A range of international agreements are being further developed and implemented in this spirit of fostering a win-win between trade and environmental objectives. I would like to put a spotlight on the constructive cooperation by producing and consuming countries of tropical timber, under the United Nations International
Tropical Timber Agreement, administered by the International Tropical Timber Organization (ITTO). Members of the ITTO work together with the private sector and civil society representatives to implement the objectives of the agreement (Table 1).

Over the years, members of the WTO have jointly developed an in-depth understanding how to reconcile trade and environment objectives in their policies and rules. The WTO dispute settlement system in numerous cases has repeatedly provided the proof of the pudding, reconfirming the rights of members to adopt and implement ambitious environmental policies. This is still work in progress, rightfully so, since enhancing synergy between trade and environment has to build upon developments in trade and trade policy, and on evolving insights in environmental challenges, as well as technological, economic and societal opportunities to protect and sustainably use biodiversity and natural resources, and combat climate change. Moreover, it requires reconciliation of different objectives, spanning all the way from providing opportunities for individual entrepreneurs to operate successfully on foreign markets, to collectively safeguarding global common goods. It has to bring together different people, preferably in an interdisciplinary approach, who are operating based on norms and rules rooted in different value systems. 
TABLE 2

\section{WTO’S DATABASE OF ENVIRONMENT-RELATED MEASURES TAKEN BY MEMBERS}

The WTO keeps a lively database of measures taken by members and notified to the WTO. The Environmental Database (EDB) contains around 13,500 environmental measures. The most frequently reported recent types of measures are: technical regulations or specifications (31\%), grants and direct payments (24\%), conformity assessment procedures $(12 \%)$, import licenses (10\%), non-monetary support $(10 \%)$, tax concessions (7\%), and ban prohibitions (7\%).

In terms of the objectives, top ranking are: chemical, toxic and hazardous substances management (16\%), energy conservation and efficiency (13\%), alternative and renewable energy (11\%), biodiversity and ecosystem management (11\%), general environmental protection (10\%), waste management (10\%), and sustainable agriculture management $(10 \%)$.

Among a wide range of other objectives are: animal and plant protection, sustainable forest management/afforestation, climate change mitigation, and promotion of environmental goods and services.

The EU and USA have notified by far the largest amount of measures (both around 2,200). All figures based on $2009-2020$ period.

SOURCE: WTO Enviromental Database. https://edb.wto.org/

Manuel A. J. Teehankee, who has documented the trade and environment debate at the WTO throughout the years, underlines that the legal basis being the main frame, attempts to further develop "hard law" can go together, or even be substituted by an effective, pragmatic "soft law". This includes dialogue, the development of guidelines, and information exchange on policies, measures and lessons learned. The latter can also inspire the first: "... all study and knowledge gathering could, in the end, lead to new rules, or the clarification of existing rules, especially in the field of potential conflict with existing trade and/or environmental practices" (Teehankee, 2000, p. 134). An excellent tool for such an informed dialogue, as well as treasure of inspirational best practices, is the environmental database kept by the WTO (Table 2).

\section{Trade \& environment - challenges}

There is no simple linear relation between trade and the environment. Global value chains are highly complex, with multiple production and trade hubs in several countries, and in many cases delivering goods to consumers worldwide. The negative and positive impacts of trade on nature and the environment are likewise difficult to assess and will be strongly dependent on local circumstances. The overall perception is that more trade will lead to more environmental damage, but this is not a given. It is obvious that more trade leads to more economic activity. The objective of trade liberalization is precisely to contribute to sustainable economic growth and the eradication of poverty. In principle, more economic activity leads to more use of natural resources and energy, throughout the chain of production - trade - consumption. At the same time, trade enhances scale, competitive production and economic efficiency. This can lead to less environmental impact per unit of product, labor or cost price. This mechanism could actually be a critical part of strategies to decouple economic growth from environmental deterioration. Trade that is more open will also increase the worldwide availability of cheaper environmentbeneficial technologies, goods and services. The overall impact of trade on the environment depends on the balance of all these effects, together with mitigating and compensating measures to offset negative impacts.

Moreover, a choice to trade or not to trade for the sake of the environment may have counterintuitive effects. Cold storing apples and pears produced in Europe for consumption off-season may seem a logical thing to do for the environment. At the same time, shipping freshly harvested apples and pears for direct consumption in 
Europe from southern hemisphere countries, where the harvest takes place counter seasonal, is relatively energy-efficient, if done by sea, not by air. One has to compare energy needed for sea-transport with keeping the fridge running for months. Whether the balance swings in favor of imports or storage depends predominantly on differences in the environmental impact of production and on the kilometers of land transport in the total journey. It is an example of having to compare apples and pears, along their life cycles.

Notwithstanding that the impact of trade has to be considered for all trade induced economic activities, let us break down some of the major environmental impacts along the three domains of the international chain, being transporting and logistics, the production of the traded goods and services, and the consumption thereof. I will not present an exhaustive list of (potential) impacts but highlight a few. Examples will be presented of measures taken by governments and companies to reduce negative impact, or even reverse it towards a positive contribution for nature and the environment.

\section{Direct environmental impact of transport and logistics}

Transportation of goods across land, water or air has several environmental impacts. It takes energy, natural resources and space to move goods from their place of production to ports, across one or more borders, to distribution hubs, and via (electronic) shops to consumers. As much as $80-90 \%$ of global trade is conducted by sea. Shipping is the most efficient way of transporting goods. At the same time, marine transportation has negative impacts on the marine environment and on humans. It leads to air and noise pollution. International shipping is estimated to be responsible for $2.2 \%$ of global anthropogenic $\mathrm{CO}_{2}$ emissions (IMO, 2018). Major problems still occur with spills of oils and chemicals, and dissolving antifoulants. Marine transport leads to cargo waste and garbage on sea and land. Ships affect wildlife, by colliding with marine animals, via underwater noise pollution, and with introductions of invasive species via the release of ballast water. Grounding or sinking ships are an overall risk to the marine environment. Ship demolition and recycling can be extremely dangerous for workers and highly pollutive. Countries work together to address these environmental concerns in the International Maritime Organization (IMO), including in the framework of the International Convention for the prevention of pollution of the sea by oil (OILPOL), as of 1954, and the International Convention for the Prevention of pollution from ships (MARPOL).

Transport over land by truck or rail has similar negative impacts on the environment in terms of energy use, air, and noise pollution. Together with handling and storage of freight, it furthermore requires vast amounts of space, where expansions result in more loss of arable land and nature, including coastal wetlands. Roads and railways are often insurmountable barriers for species, frustrating there needs to move around and migrate. As such, infrastructure leads to loss, fragmentation and isolation of remaining natural areas. In such cut offs, populations of animals and plants will in the end dwindle or disappear completely.

Such impacts can and have to be prevented, mitigated and/or compensated as much as possible. This requires sound planning and environmental impact assessments, as well as making full use of innovative environmental technologies and smart logistics. One of the major challenges for the marine and land transport sector will be to substantially reduce, and as an end objective phase out, the use of fossil fuels and related impact on our climate. IMO is committed to a reduction of $\mathrm{CO}_{2}$ emissions per transport work (carbon intensity), as an average across international shipping, by at least $40 \%$ by 2030, pursuing efforts towards $70 \%$ by 2050 , compared to 2008 . It also aims for a reduction of the total annual greenhouse gas emissions from international shipping by at least $50 \%$ by 2050 compared to 2008, while, at the same time, pursuing efforts towards phasing them out. 
TABLE 3

\section{INTEGRATING THE ENVIRONMENT IN TRADE FACILITATION: MOMBASA PORT}

Part of TMEA's agenda is to make East-Africa's ports more efficient and greener. It has for example enabled Mombasa Port in Kenya to mitigate and adapt to climate impacts. Results achieved include removal of asbestos, efficient and green transport logistics through modal shift from road to rail, planting of trees, eco-terra slope protection, improvement of water supply and waste management, and infrastructure improvement such as eco-friendly conveyor belts. A solar power plant has been installed at the port, generating $410 \mathrm{KW}$ of green energy per day for use in workshops and offices. New technologies such as Eco-Hoppers and Mobile Harbour Cranes, have improved labor conditions, contributed to greening the port, and increased port efficiency. The hoppers speed up operations due to their ability to scoop and load more cargo. Ships that would take 10 days to offload clinker are now served within half the time. It has significantly improved resource efficiency. In addition, trucks move faster in and out of the port.

SOURCE: https://www.trademarkea.com/market-access/mombasa-port/

Much trade in services, including tourism, is related to people travelling abroad, categorized as "Mode 1 Cross border trade" under the WTO General Agreement on Trade in Services (GATS). For long distances or because of time efficiency, such services will often be provided by air. Services provided in one country to the service consumer in another country, being "Mode 2 Consumption abroad", such as international consultancies, nowadays depend heavily on the internet. This may offset the need to travel but sending bits and bytes and using the internet goes together with substantive energy use as well.

Reducing environmental pollution of transport as of today, while decoupling it from the growth in transport needed for the increase in trade in the near future, is a major challenge. All stakeholders have to act beyond technological improvements, such as increased efficiency of fossil-fuel engines of planes, vessels, trucks, trains, cranes and conveyors. It will require a redesign of transport and logistics itself.

The good thing is though: smart, sustainable transport is serious money. Less waiting time, with speedy transport and handling are good for business. For perishable goods, like fruit, vegetables and flowers, time lost is an erosion of quality, with heavy risks of completely losing the license to sell. Efficient logistical flows save business and are good for the environment. They reduce both overall pollution, as well as environmental impacts per unit of product transported. Guided by the
WTO Trade Facilitation Agreement, countries streamline trade. Trade facilitation - transparent, predictable and efficient border procedures that expedite the movement of goods - reduces handling time and administrative "red tape". It allows firms to minimize losses of perishables, cut inventory costs, be more responsive to changing consumer preferences, and participate in time-sensitive global value chains. Lowering trade costs is very beneficial, also for small firms, and increases opportunities for start-ups and small companies to move from the informal to the formal economy, and to grow their businesses. This can be highly beneficial for female entrepreneurs and workers, who tend to operate more in the informal economy.

The inherent positive effect of trade facilitation on the environment can be amplified if it goes together with measures that lower the environmental footprint of transport and logistics. Trade-Mark East Africa (TMEA), for example, conducts detailed assessments of environmental, climate change and social risks and impacts. TMEA works closely with East African Community (EAC) institutions, national governments, the private sector and civil society organizations to increase trade by reducing barriers to trade and increased business competitiveness. It has built up a strong track record in trade facilitation (Table 3).

Notwithstanding the obvious responsibility for traders to continue to lower the environmental footprint of the trade process, it is difficult to reason that trading 
in itself is bad (or good) because of its environmental footprint. As mentioned above, the overall impact of trade induced economic activities on the environment is complex, with the actual effect of transport and handling in most cases being relatively low, compared to that of production and consumption.

\section{Trade, consumer demands and the environment}

Trade can only be socio-economically viable if it is responsive to consumer demands: specific products and services will (continue) to be imported in a country of final destination, depending upon the interest of consumers willing and able to buy them. There is an important condition attached to this: consumers have to be in a position to make informed choices. They need reliable information on the type of product offered, and its quality and price, as well as the relative price-quality ratio compared to other related products. One of the major advantages of international trade to consumers is exactly this. Trade brings products and services from abroad within reach of consumers worldwide. It reinforces competition and efficient production, resulting in lower prices. If trade is guided by sound governmental rules and private sector standards, it will lead to better quality of products and services.

Over the past years, consumers are increasingly interested to be fully informed on such direct, "physical" quality features. They are also eager to know where the product they intend to buy comes from, and who is behind the service provided. This requires transparency in the value chain and internationally agreed standards on reference to origin. In addition, more and more consumers need to know whether producers, traders and sellers have duly respected sound labor conditions and environmental protection, throughout the entire international trade value chain.

We cannot overstate the importance of this trend that consumers more and more "need to know" for social justice and environmental protection. It swings the balance further away from the classical disposition, in which producers and traders serve what they deemed well enough on the plate of consumers. For sure, also supply still triggers demands and there are major market failures, like insufficient competition or lack of opportunities for pricing mechanisms that include proper compensation of progressive investments in social justice and environmental management. Nevertheless, there is an increasing push back from consumers, supported by citizens, civil society organizations and politicians. The consumer dictates the requirements of a license to operate in production and trade.

Smart businesswomen and men get the message. They will continue to ensure and improve the physical quality of their product. They will abide by international governmental standards, for example, maximum residue levels of pesticides and limitations on food preservatives, including those under the framework of the Codex Alimentarius, administered by the Food and Agriculture Organization and World Health Organization. If needed, they will actively support the use of more advanced or additional quality standards. Responsive entrepreneurs will also meet the desire of consumers to be informed, by providing reliable, independently verified information on the origin of the product and whenever possible its components. They will meet demands on how production, handling and trade have been conducted in conformity with independently verifiable criteria for economic, social and environmental sustainability. Meeting consumer demand in such a manner, with top quality, authentic products and services has become a societal value, deserving fair rewards for all who create and uphold this value (Table 4).

\section{Sustainable production for trade}

The above illustrates how trade itself is more than a logistical tool to deliver a good or service from producers to consumers. Trade is more becoming a central node, linking values of consumers and markets to producers. Vice versa, trade operates as the delivery mechanism for dedicated producers with their values, also guided 
TABLE 4

TRACE AND TELL

Nature \& More is a trading company in fresh organic fruits and vegetables from all over the world. It is considering itself a "trace \& tell" consumer trademark. The company profiles online grower's stories, and full transparency about their commitments and efforts towards planet and people. Nature \& More wants to empower consumers to make informed purchasing decisions in an anonymous market. The company keeps track of the positive impact of its product sold in terms of $\mathrm{CO}_{2}$ reduced, water saved and saved soils. Consumers find a unique number of the grower on the product they want to buy. With this number, they can watch a video of the grower on the website, see pictures of the farm or read an interview. There is substantive information on the farm and farming methods used. Consumers can give feedback to the farmer. The website also contains recipes.

SOURCE: Nature and More. https://www.natureandmore.com/

by norms in their country, to meet consumers values. This is easily said, but for many, in particular smaller companies difficult to achieve. They are constrained by opportunities they have, like: up to date knowledge, a skilled workforce, and access to technology and capital. They need market information and sufficient market power to ask for a fair price, doing justice to investments made to reach out above minimum legal requirements in recognition of consumer demands. Many global value chains are complicated, with many players involved in different countries.

Chocolate is an extreme example of a product based on many ingredients, from different countries, handled by several intermediaries. There is an extreme disconnect between primary producers and end users. Many cocoa farmers never had the opportunity to eat chocolate. The vast majority of chocolate eaters has never met a cocoa farmer or seen a cocoa tree. Moreover, chocolate is among the most emotionally valued consumer goods in the world. Retailers and producers of chocolate realize that consumers are seeking reassurance that the chocolate they give as a present and eat is okay. Independent voluntary certification schemes offer a strong mechanism for accountability, such as fair trade, Rainforest Alliance and organics.

Most requirements of consumers are passed on to farmers, far away on the other side of the value chain.
Millions of cocoa farmers are very poor, struggling to make a living for their families. Clearly, global trade here is way beyond just delivering cocoa from point $A$ to point $B$. The chain linking farmers to consumers is truly a global chain, where values of consumers, traders and producers have to be aligned. Trade has to be a force for good: for farmers and workers to own a decent living, and for conduct in full respect of nature and the environment, and for consumers to truly enjoy a most delicate food. All involved have to pay a true price (Table 5).

\section{Integrating trade, environment and labor}

A push to environmentally friendly trade in goods and services can also back up the required transformation of labor markets. A green economy will be one with green jobs, by workers operating in decent working conditions, with proper rewards and under social protection. Young people show a strong preference to work for companies that take sustainability at heart. Young start-ups develop remarkable refreshing, innovative products and services, based on the highest standards for sustainability.

The transition to a green labor market is unavoidable and very much desired. It goes hand-in-hand with a comparable ( $r$ )evolutionary development, being the digitalization of our lives, work and economy. However, it is pertinent that workers get the opportunity to adjust their skills. If needed they have to be able to find fair 
TABLE 5

\section{JOINING FORCES FOR SUSTAINABLE COCOA AND CHOCOLATE - CASE OF THE NETHERLANDS}

The Netherlands is ranking top in global cocoa trade, logistics and processing, and is actively bringing supply and demand together. Ever since 2010, companies operating in the Netherlands, civil society organizations, research and the government are joining forces for sustainability in the cocoa value chain worldwide. Under the Dutch Initiative on Sustainable Cocoa (DISCO, 2020), stakeholders individually and in public-private partnerships are aiming to improve the livelihood of cocoa farming families, and to enable them to earn a living income. DISCO parties are committed to the prevention and elimination of all forms of child labor (Sustainable Development Goal 8.7). They have made substantive progress to make cocoa and chocolate products consumed in the Dutch market guaranteed sustainable cocoa. The applied principles for a sustainable cocoa economy also include environmental objectives: sound land use planning; wise management of natural resources; and conservation and wise use of biodiversity, including by stopping deforestation and forest degradation.

SOURCE: DISCO (2020).

opportunities to move away from their present jobs at stake. We need to make such rearrangements, for example to make the transition from a fossil fuel to a carbon-neutral economy.

Fair alternatives to workers to take up new responsibilities or move to a new job, will also increase societal support for a green transition. This is also affecting support for trade policies, or even the perception of the value of trade itself. One can hardly ignore that recent sentiments leaning towards trade protectionism, have as a root cause that labor markets are inherently for some categories of workers, in some sectors, and some regions, far less flexible than for others. What needs to be rightfully so protected though is the worker, not jobs that in the end are no longer adding economic and societal value.

This requires integrated strategies and intensive cooperation between all that have responsibilities in trade, labor and the environment: politicians, governments, workers and employers and their representatives, and civil society organizations. It can be complicated to design a win-win-win of trade/economy, environment and labor. It can be hard to openly identify losses and adjust to those. Scientists can be helpful to get the figures right and make assessments of policies and action plans. At the global level, the International Labour Organization (ILO) provides valuable guidance on this to its tripartite membership, including with state-of-the-art publications like the World Employment and Social Outlook 2018: Greening with jobs and 2021: The role of digital labour platforms in transforming the world of work (ILO, 2018, 2021).

\section{Developments in business thinking}

The way the private sector perceives their own responsibility for the environment has substantially changed over the past decades. There is of course enormous diversity among companies, small or big, start-up or with a long track record. Businesswomen and men around the world operate under very different circumstances, meeting demands of all kinds of consumers. There are major differences embedded in the wide variety of economic sectors and products. This is reflected in the so-called Harmonized System of the World Custom Organization, which is fundamental for trade agreements. The system comprises an international nomenclature arranged in six-digit codes, allowing for the common classification of trade goods. Countries can expand the list beyond the six-digit level. It comprises over 5,000 commodity groups.

It is impossible to do justice to the diversity of companies' views, let alone in a historic context. However, in broad terms, several dimensions can be described in business' appreciations of environmental 
protection. Basically, companies will have and want to abide by minimal legal requirements that are aiming at their direct business operations, which should do no harm to the environment. Whereas the responsibility rests upon the shoulders of companies, many governments promote full implementation of environmental standards. They are also responsible for enforcement, both inherently to protect the common good and to ensure that environmental requirements are met by all companies, thereby keeping a level playing field. Over the years, countries have harmonized environmental protection requirements internationally in Multilateral Environmental Agreements (MEAs), such as for hazardous waste, ozone, climate change and nature protection. National governments have adopted more, and more stringent environmental laws, also to take into account specific local environmental vulnerabilities. Regional and bilateral trade agreements are now more commonly used to both strengthen joint ratification and full implementation of MEAs, and to synchronize such additional environmental requirements.

In the last decades, companies have started to fully embrace environmental measures that lead to efficiency gains, whether or not in conjunction with legal requirements. With innovative technologies and smart use of energy, water and natural resources, they do good for the environment, and improve their economic performance. Moreover, companies adopt Corporate and Social Responsibility (CSR) policies, often under the responsibility of small staff units. With CSR, companies take up measures in support of sustainability in a structural manner. They enhance transparency, for which they can rely on international frameworks, such as the Global Reporting Initiative $(\mathrm{GRI})$. As an independent international organization, GRI helps businesses and other organizations to take responsibility for their impacts, by providing a common language to communicate those impacts. GRI works with over 10,000 reporters in more than 100 countries. Countries have developed legal requirements for impact reporting. The European Union is developing obligations for a due diligence approach, along the entire value chains in which companies are involved.

Doing no harm, and doing good for the environment are laudable. Nevertheless, business is increasingly becoming aware that their long-term value generation is linked to global sustainable development challenges. Climate change, the critical state of biodiversity, poverty and hunger, and rising inequality are threatening the mere existence of their business. The COVID-19 pandemic has brought vulnerabilities to light.

This has brought the World Business Council for Sustainable Development to take a bold step. With its Vision 2050 - Time to transform: How business can lead the transformation the world need, WBSCD is calling "to adopt radically different mindsets, implement innovative practices, and make bold new investments that can fundamentally change the trajectory of business and society toward a world in which 9+ billon people can live well within planetary boundaries by mid-century" (WBCSD, 2021). The transformation will depend on three shifts in strategic business mindsets:

\section{Mind shift 1 - Reinventing capitalism to} reward true value creation, rather than value extraction;

Mind shift 2 - Resilience: enhancing business' capacity to anticipate, embrace, and adapt; and

Mind shift 3-Regeneration: moving beyond a "doing no harm" mindset to one in which we build the capacity of our social and environmental systems to heal and thrive.

WBCSD has elaborated on these mind shifts. It has developed a vision and action plan with transformative pathways including for energy, transportation \& mobility, product \& materials, water \& sanitation, and food. It is a remarkable step for a CEO-led organization committed to sustainable development of over 200 companies, including major multinationals. 
Companies striving to be good can also benefit from opportunities trade offers and find new markets. Environmentally friendly trade has become part of competitiveness in global value chains. There are costs to become green, but it is a strong license to produce, trade and sell. It pays off, although there are still major market imperfections. It is hard to reflect social and ecological values in the price of goods and services.

It can be even more difficult for small businesses to be good for the environment, worldwide accounting for about $90 \%$ of businesses and more than $50 \%$ of employment. The International Trade Centre (ITC) is supporting small and medium-sized enterprises (SMEs). Considering the results of extensive surveys among small businesses, ITC has compiled convincing arguments for SMEs to go green in its SME Competitive Index 2021 - Empowering the Green Recovery (ITC, 2021). Going green is both a survival imperative and a business opportunity. The COVID-19 pandemic has made it even more pertinent for SMEs, who have suffered heavily. Firms trading across border were hampered by domestic restrictions and were more exposed to shocks in partner countries. At the same time, internationally trading firms showed greater capacity to adapt and respond. Like WBCSD, also ITC identifies the need for business to increase their resilience. Companies need to have robust management and operations, invest in connections to access resources and support, and be responsive with inventive, well-adapted strategies.

ITC identifies three pillars of a green competitiveness framework: enhanced ability to compete; better connect with buyers and suppliers; and enhanced capacity to change in response to global environmental challenges. Five factors can drive SME business to go green:

1) Increased resilience: with targeted investments and improved business operations, management practices and business models.

2) Cost reductions and higher productivity: use less resources lowers costs and improves profits.
Eco-technologies and reducing/reusing waste lead to more efficient production.

3) Compliance with regulations: adjust practices to stay ahead of the curve.

4) Access to markets: go green and sell to environmentally conscious buyers. Certification to sustainability standards is a license to trade and can open lucrative new opportunities; and

5) Eligibility for green financing: with green business and shovel-ready climate and environment projects, SMEs can benefit from green investments.

It is encouraging to see that SMEs continue to act: they reduce waste, convert to green energy, make green products and services, gain green certificates, etcetera. Nearly $60 \%$ of surveyed African companies that had greened their enterprises said it led to new, higher quality and more products, and going digital. They were also better positioned to receive green finance.

There are striking similarities between the mind shifts put forward by WBCSD, an organization primarily of large companies, and the pathway to green recovery in support of smaller companies, promoted by ITC. Both resonate with a growing number of entrepreneurs, small or big, who have started or transformed their business to make a positive contribution to protect nature and the environment.

\section{Emerging issues}

Many of the major 'trade \& environment'-issues have a long history. I have mentioned several classics, which are structurally rooted in international cooperation, like preventing oil pollution at sea (IMO since 1954), promoting trade in tropical timber from sustainably managed forest (ITTO since 1983), and mutual supportiveness between international trade and environmental law (WTO since 1995). Recently, new issues are emerging, or re-emerging and placed on the agenda. Several countries are engaged in structured discussions on Trade and Environmental Sustainable Development (TESSD). I will mention 
FIGURE 2

\section{CIRCULAR ECONOMY, SAME INGREDIENTS, FUNDAMENTAL DIFFERENT RECIPE}

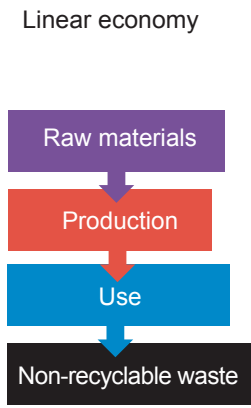

In a linear economy, raw materials are extracted from the earth, used and discarted: "take-make-waste". At best, this economy leads to the relative decoupling of economic Growth from the use of natural resources.

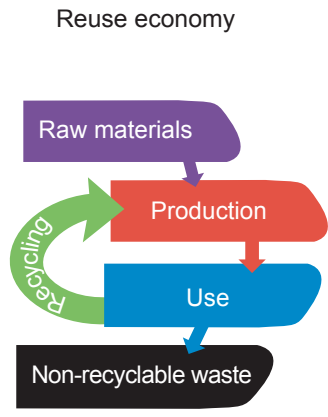

In the reuse economy, many non-recyclable materials are used again (cascading, repair/maintenance, reuse, remanufacturing, recycling). At best, this reuse economy leads in part to an absolute decoupling of economic growth from the use of natural resources and from emissions: the demand for natural resource and the emissions decrease as the economy grows.

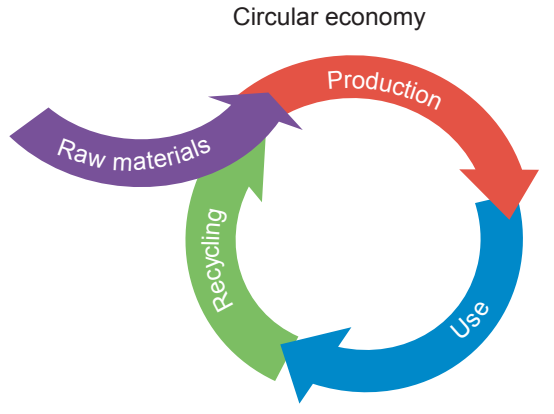

The ideal picture is a circular economy in which raw materials are never depleted. This economy can be structured so that there is a positive coupling between economic growth and the growth of natural resources (negative emissions/positive footprint). In a circular economy, value chains will be organized differently.

SOURCE: Ministry of Infrastructure and the Environment and the Ministry of Economic Affairs. A Circular Economy in the Netherlands by 2050 Government-wide Programme for a Circular Economy.

some prominent issues featuring at the WTO: circular economy, environmental goods and services, environmentally harmful subsidies, and carbon border adjustment mechanisms.

\section{Circular economy}

One of the most inspiring developments of the last years is the awareness that we have to get the circular economy rolling, and that we can do so. The circular economy is a means to ensure that our consumption and production remains within the carrying capacity of this planet. It creates new economic opportunities for businesses. Incorporating circularity principles into global supply chains makes us look differently at material flows and services. Global trade networks can help to scale up circular innovations, reduce environmental impacts and increase social benefits through inclusive development. The recipe for a circular economy follows a careful application of smart design, responsible use (not waste) of resources and energy, sound recycling capacity, and innovative use of recycled content (Figure 2).

Many countries have taken the concept of a circular economy up in their vision, strategies and action for sustainable development.

However, we need joint international efforts to make the trade system conducive for markets of circular innovations. Trade barriers can be removed, for example, if such barriers are based on the notion of trade in waste, whereas in a circular economy such "waste" is actually a source to recycle. At the same time, moving to a more circular economy will redirect trade flows, with potential negative impacts for some countries, including 
developing economies who are heavily depending on trade in commodities. Developing economies could also run the risk of increased import of waste exceeding their recycling capacity. However, a shift in trade towards products that meet circular economy standards also present new opportunities for job creation and economic development, especially in emerging services industries like recycling, repurposing and re-use of materials. It could lead to new opportunities for commoditiesdependent countries, offering an alternative strategy to the traditional manufacturing-led export model for industrial development. Van der Ven (2020) has published a paper, upon request of the Permanent Representation of the Kingdom of the Netherlands in Geneva, which provides an understanding of the linkages between the circular economy, trade, and development. She refers to various tools available to developing economies to leverage opportunities and mitigate any negative spillovers.

Looking at the circular economy from the business perspective: this concept can be directly applied by companies, in support of their (new) sustainable business model. It will enable effective (re)use of local resources. Circular business may redirect trade opportunities, but trade can also enable full use of innovative, state-of-the-art and competitive solutions at the local, national, regional and global scale.

\section{Environmental goods and services}

Some goods and services are less harmful to the environment than others are. Environmental goods and services are those that can contribute to improving the quality of the environment, managing natural resources, and reducing material consumption and pollution. Trade in environmental services can support both trade and environmental objectives. Several WTO members support restarting negotiations to reach agreements to reduce or, as appropriate, eliminate barriers to trade in environmental goods and services. As of 2001, following the Doha Ministerial Declaration, WTO members have attempted for many years to agree on an Environmental Goods Agreement (EGA). Lacking support by all members, 46 WTO members (including the EU) continued negotiations, accounting for the majority of global trade in environmental goods. They worked out a draft with the clear objective to bind and eliminate tariffs on environmental goods, such as those relevant for generating clean and renewable energy, improving energy and resource efficiency, controlling air pollution, managing waste, treating wastewater, monitoring the quality of the environment, and combatting noise pollution. Unfortunately, negotiations stopped at the end of 2016, primarily because WTOmembers could not agree on the categories of goods to be included in the list.

Nowadays, several countries propose to continue negotiations. An option is to focus on a range of goods with a clear track record of having a positive impact on the environment, for example goods in support of solar and wind energy, or wastewater treatment. However, opening trade also for components, capital goods and services, required for environmentally friendly goods, could have a strong multiplier effect. Countries propose to also address non-tariff measures. They would like to make sure that government regulations, rules and directives are as supportive as possible to improve environmentally friendly trade. These include for example rules for import licensing and for valuation of goods at import. If implemented in a bureaucratic or overly burdensome manner, trade can also be unnecessary hampered by rules of origin to define where a product was made, and quality conformity standards and practises, like shipment inspections.

In the same vein, countries suggest to liberalize trade in environmental services. These could include, as mentioned, services related to environmental goods, like consulting services on the appropriate use of goods, technical support, and research \& development. It is logical to also include services that as such have a merit for environmental protection, for example advice on environmental planning or impact assessments. 
The European Union proposes a broad scope, beyond classical environmental services sectors, as many services end up feeding into environmental projects, generally as part of integrated business solutions. This means liberalization of trade such as in ecoengineering, construction, and architectural services. The EU also favours inclusion of services that are relevant for circular economy-related business models, such as maintenance, repair and recycling services.

\section{Redirecting environmentally harmful subsidies}

Subsidies can be a powerful tool in favor of environmental protection. If they are directly interfering with economic operations, the provision of subsidies may have impacts on opportunities for global trade. The WTO Agreement on Subsidies and Countervailing Measures applies to subsidies that are specifically provided to an enterprise or industry or group of enterprises. The overall principles of nondiscrimination of the WTO apply. Subsidies in support of environmental protection or enhancing environmentfriendly production are possible, as long as they are developed in accordance with principles laid down in these agreements, including non-discrimination, and the need for specificity and transparency. The WTO Agreement on Agriculture guides the use of agricultural subsidies and provides for specific rules. Agricultural export subsidies are prohibited. There are strict rules for domestic agricultural support measures, which have to be gradually reduced and made less trade-distorting. The so-called Green Box of subsidies that have no, or at most minimal trade-distorting effect, enables subsidies for inter alia payments under environmental programs, and conservation and sustainable use of biological diversity.

There are major initiatives to further elaborate rules for ensuring that subsidies are in line with WTO principles, as well as with the need to protect nature and the environment, by delineating those subsidies clearly "do no harm", and as much as possible "do good".

WTO members are negotiating disciplines to eliminate subsidies for illegal, unreported and unregulated fishing, and to prohibit certain forms of fisheries subsidies that contribute to overcapacity and overfishing. The negotiations are based on the mandate from the WTO's 11th Ministerial Conference held in Buenos Aires in 2017 , and from the United Nations Sustainable Development Goal 14.6. ${ }^{2}$

The draft agreement contains a prohibition on subsidies to Illegal, Unreported and Unregulated (IUU) fishing, as well as for fishing or fishing related activities regarding overfished stocks. Furthermore, it is proposed not to grant subsidies contributing to overcapacity and overfishing. The draft agreement contains a list of such subsidies, including for construction, acquisition or modernization of vessels; subsidies for machines and equipment of vessels; subsidies to the purchase of fuel, ice or bait; subsidies to costs of personnel; and income support of operators or workers. There will be granted special and differential treatment to developing countries, in particular Least-Developed Countries (LDCs). It may include transition periods, exemptions for small-scale subsistence fishing and technical assistance to implement the fisheries subsidies disciplines.

Agrowing number of countries, following commitments by G20 ministers and inspired by the Friends of Fossil Fuel Subsidy Reform (which includes the Netherlands) want to develop international disciplines regarding fossil fuel subsidies. This, in line with global commitments to combat climate-change and move towards low greenhouse gas emissions and climateresilient development. They recognize that inefficient

\footnotetext{
2 Sustainable Development Goal (SDG) 14.6: "by 2020, prohibit certain forms of fisheries subsidies which contribute to overcapacity and overfishing, and eliminate subsidies that contribute to IUU fishing, and refrain from introducing new such subsidies, recognizing that appropriate and effective special and differential treatment for developing and least developed countries should be an integral part of the WTO fisheries subsidies negotiation."
} 
fossil fuel subsidies, estimated at USD 500 billion in 2018, encourage wasteful consumption, disadvantage renewable energy, and depress investment in energy efficiency. Countries should phase out such subsidies as soon as possible. ${ }^{3}$

Effectively addressing fossil fuel subsidies as a whole will deliver trade, economic, social and environmental benefits. It can also release funds for other development priorities. Energy subsidy reforms will have to be conducted taking fully into account the specific needs and conditions of developing countries and minimize the possible adverse impacts on their development, in a manner that protects the poor and the affected communities. Several countries are working on a joint commitment at the WTO to address the trade-related aspects of fossil fuel reform. This would include starting with sharing more information on financial support given for exploration, production or use of fossil fuels.

There are still intensive discussions on how to reform energy policies, meeting the triple objectives of ensuring energy for all, while moving to carbon neutrality, and protecting biological diversity. It is clear though that we are on turning point in history of humanity and planet earth: we have started the phase out of fossil energy, including by abolishing perverse subsidies for fossil fuels. Producers, traders and consumers need to be given time to accommodate to new rules. However, they will act ethically sound and economically smart if they start to take the transformation of their energy use in their own hands now.

\footnotetext{
${ }^{3}$ These countries build there proposal on Sustainable Development Goal (SDG) 12.6: "Rationalize inefficient fossil fuel subsidies that encourage wasteful consumption by removing market distortions, in accordance with national circumstances, including by restructuring taxation and phasing out those harmful subsidies, where they exist, to reflect their environmental impacts, taking fully into account the specific needs and conditions of developing countries and minimizing the possible adverse impacts on their development in a manner that protects the poor and the affected communities". For subsidies, they do bring this much further, calling for elimination of such subsidies and doing so under a binding international agreement.
}

\section{Climate change - carbon border adjustment mechanisms}

As is the case for addressing other environmentrelated challenges, global trade policy can go handin-hand with measures to combat climate change. As mentioned above, trade can catalyze the transition towards low-carbon, circular economies. Trade in environmental goods and services can be given a preferential status. These measures will complement the competitiveness of green production and consumption, in combination with rules, subsidies and taxation aiming for the reduction of greenhouse gas emissions.

One of the major challenges is how to introduce measures that discourage trade in certain goods with a substantive negative impact on climate and that are more carbon-intensive compared to local products. Imports of such goods would offset efforts by economic actors in the country concerned, who have been or are making substantive investments to reform their operations to reduce the carbon footprint. Without additional measures, production could even be transferred to other countries with lower ambition for emission reduction. If this happens, there will also be no net reduction in global emissions. This will frustrate efforts of countries and their industries to contribute to the global climate objectives of the Paris Agreement.

The European Union, in the context of the European Green Deal, has elaborated a carbon border adjustment mechanism in conformity with WTO rules and principles. The "CBAM" (European Commission, 2021), places a carbon price on imports of certain goods from outside the EU, as a way to reduce the risk of such "carbon leakage" by encouraging producers in non-EU countries to green their production processes. EU importers will buy carbon certificates corresponding to the carbon price that would have been paid, had the goods been produced under the EU's carbon pricing rules. Conversely, once a non-EU producer can show that they have already paid a price for the carbon used in the production of the imported goods in a third 


\section{FIGURE 3}

TRADE, NO HARM, DO GOOD, BE GOOD

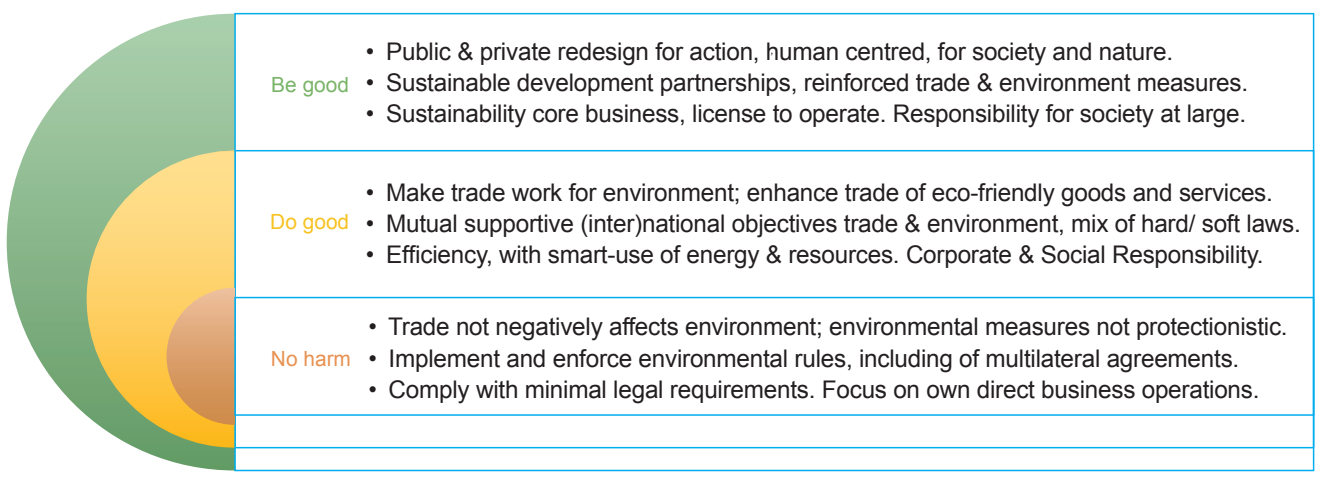

SOURCE: Own elaboration.

country, the corresponding cost can be fully deducted for the EU importer. Also, Canada is considering the introduction of border carbon adjustments, to ensure that regulations on a price on carbon pollution apply fairly between trading partners (Department of Finance, Government of Canada, 2021).

Several countries are rather worried that CBAMs will hamper trade in a manner that is not respecting WTO-objectives and rules. They are not convinced that alternative measures have been exhausted. Clearly, there is a need to continue to exchange information among WTO members, for a common understanding how to integrate the dual objective of tackling climate change and promoting trade, in a manner that supports sustainable development.

\section{Concluding remarks: no harm, do good, be good}

It is encouraging that the deliberations on the interface between trade and the environment have moved far beyond the questions whether this is an issue for either the trade or the environment community. Furthermore, it is widely accepted that trade and environmental policies can and have to operate in a mutual supportive manner. In this article, I have illustrated that win-win solutions are not always easy and do require innovative thinking. We can build upon decades of experience in policies and practice, following the principle that trade should do no harm to the environment, and vice versa, that measures for environmental purposes should not constitute a means of arbitrary or unjustifiable discrimination or a disguised restriction on international trade. We can rely on a track record of hard and soft rules, and moreover, businesses taking up their social, environmental and corporate responsibility to do good: to make trade work for the environment and enhance opportunities for trade in environmentally friendly goods and services (Figure 3).

In this article I have highlighted what trade and trade rules mean to people. As such, it is also a reflection of the growing recognition that trade professionals have to (better) illustrate how trade affects people. We have to make clear who benefits, and who does not; 
and how trade policies, and complimentary economic, social and environmental policies, can reduce, mitigate or compensate losses amplified by trade. It also implies that we have to critically review, and if needed revise, rules and regulation to better meet the needs of people, be it as citizen, consumer, worker or entrepreneur.

The COVID-19 pandemic is adding up to daunting global challenges facing us, of poverty, hunger, inequality, climate change and biodiversity loss. Challenges threatening our well-being, but moreover the lives of the next generations. Tackling these challenges and transforming them in opportunities requires us to transform our lives, societies, and economies to be truly sustainable, for people and planet, where we redirect our profits to this cause. It is a call to each of us and to join forces. In other words, we have to embrace as citizens, consumers, workers, and entrepreneurs what is the existential objective in our private life: do no harm, make sure to do good, and continuously improve ourselves to be good.

\section{Bibliographic references}

Department of Finance, Government of Canada. (2021). A Recovery Plan for Jobs, Growth and Resilience - Budget 2021 (see: paragraph 5.3 Advancing Canada's Climate Plan).

DISCO, Dutch Initiative on Sustainable Cocoa. (2020). Declaration DISCO. https://www.idhsustainabletrade.com/ initiative/dutch-initiative-on-sustainable-cocoa-disco/

European Commission. (2021). Proposal for a Regulation of the European Parliament and of the Council Establishing a Carbon Border Adjustment Mechanism. COM(2021) 564 final. Brussels.
ILO, International Labour Organization. (2018). World Employment and Social Outlook 2018: Greening with jobs. ILO - Geneva.

ILO, International Labour Organization. (2021). World Employment and Social Outlook 2021: The role of digital labour platforms in transforming the world of work. ILO - Geneva.

IMO, International Maritime Organization. (2018). Action to Reduce Greenhouse Gas Emissions from International Shipping. Implementing the Initial IMO Strategy on Reduction of GHG Emissions from Ships. IMO - London.

ITC, International Trade Centre. (2021). SME Competitive Outlook 2021. Empowering the Green Recovery. ITC - Geneva.

Ministry of Agriculture, Nature and Food Quality, The Netherlands. (2010). Letter of Intent Sustainable cocoa consumption and cocoa production.

Permanent Representation of the Kingdom of the Netherlands to the UN and International Organizations in Geneva. (2020). The Netherlands promotes trade for sustainable development. \#NLtrade4good

Teehankee, M. A. J. (2020). Trade and Environment Governance at the World Trade Organization Committee on Trade and Environment. Kluwer Law International B. V.

UNCBD, United Nations Convention on Biological Diversity. (2000). Cartagena Protocol Biosafety.

UNCTAD, United Nations Conference on Trade and Development. (2006). International Tropical Timber Agreement. TD/TIMBER.3/12.

Van den Bossche, P., \& Prévost, D. (2021). Essentials of WTO Law. Second edition. Cambridge University Press.

Van der Ven, C. (2020). The Circular Economy, Trade, and Development: Addressing spillovers and leveraging opportunities. Tulip consulting.

WBCSD, World Business Council for Sustainable Development. (2021). Vision 2050. Time to transform. How business can lead the transformation the world needs. WBCSD - Geneva.

WTO \& UN Environment, World Trade Organization, \& United Nations Environment. (2018). Making trade work for the environment, prosperity and resilience. WTO - Geneva and UN Environment - Nairobi. 